\title{
Optimizing the use of oxytocin on labor and delivery
}

\author{
Oxytocin is the most common hormone administered in obstetrics. \\ Reducing variation in the use of this agent will improve patient safety.
}

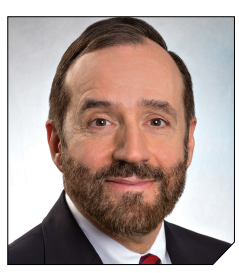

Robert L. Barbieri, MD

Chair Emeritus, Department of Obstetrics and Gynecology

Interim Chief, Obstetrics

Brigham and Women's Hospital

Kate Macy Ladd Distinguished Professor of Obstetrics,

Gynecology and Reproductive Biology

Harvard Medical School

Boston, Massachusetts xytocin is the hormone most commonly administered to women on labor and delivery. It is used for induction of labor, augmentation of labor, and to reduce the risk of postpartum hemorrhage. Licensed independent prescribers, including physicians and nurse midwives, order oxytocin, and licensed professional nurses execute the order by administering the hormone. Optimal management of oxytocin infusion requires effective interprofessional communication and collaboration. During labor it is common for disagreements to arise between the professionals ordering and the professionals administering oxytocin. The disagreements are usually caused by differing perspectives on the appropriate oxytocin dose. Standardized protocols and checklists reduce practice variation and improve patient safety.

\section{Oxytocin hormone}

Oxytocin is a cyclic nonapeptide synthesized in the hypothalamus

doi: 10.12788/obgm.0061

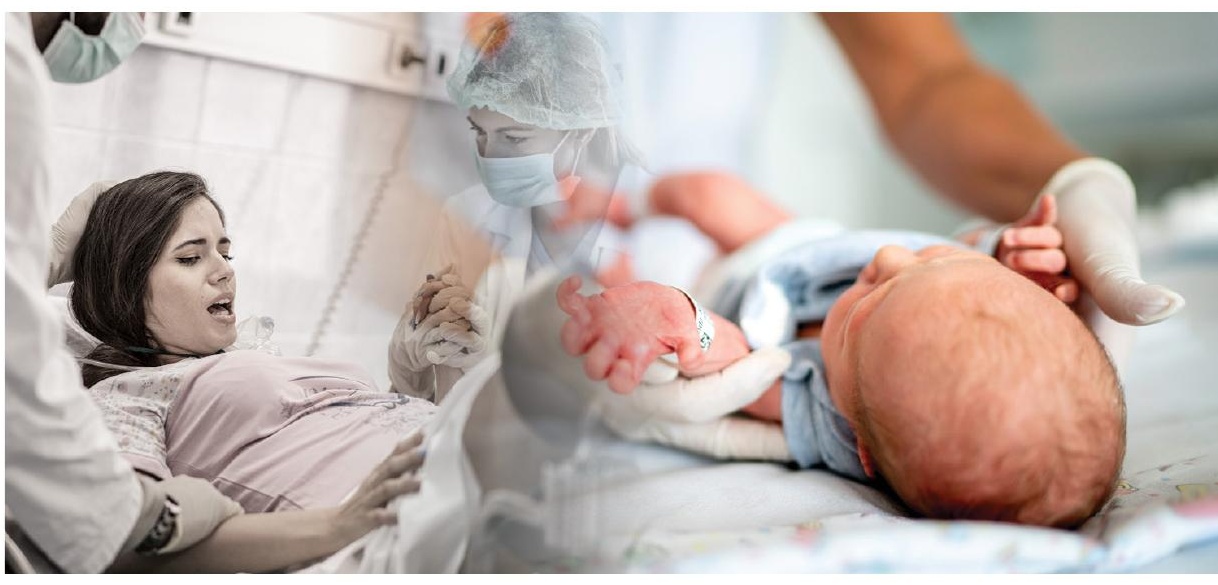

and secreted into the circulation from axonal terminals in the posterior pituitary. In the myometrium, oxytocin activates a membrane $G$ protein-coupled receptor, increasing phospholipase $\mathrm{C}$ and intracellular calcium. Following several intracellular chemical cascades, oxytocin stimulation results in myosin and actin filaments sliding over each other initiating shortening of the smooth muscle cell. Myometrial smooth muscle cells are connected by gap junctions, facilitating the coordinated contraction of the uterus. ${ }^{1}$
Oxytocin pulse frequency and uterine oxytocin receptor concentration both increase during pregnancy and labor, facilitating the birth process. Oxytocin pulse frequency increases from 2.4 pulses per hour before labor to 13.4 pulses per hour in the second stage. ${ }^{2}$ In addition, uterine oxytocin receptor concentration increases 12-fold from the early second trimester of pregnancy to term. ${ }^{3}$

Oxytocin has a half-life of approximately 10 to 15 minutes. Many pharmacologists believe that for a given dose of a drug, it takes 4 to 5 half-lives for a stabilized 
circulating concentration to be achieved. Therefore, during an oxytocin infusion, when the dose is increased it may take 40 to $50 \mathrm{~min}$ utes to achieve a new higher, stabile circulating concentration. ${ }^{4}$

\section{Low-dose vs high-dose oxytocin protocols}

Oxytocin is often used in a premixed solution of 30 units of oxytocin in $500 \mathrm{~mL}$ of lactated Ringer's solution. With this mixture, an infusion of $1 \mathrm{~mL} /$ hour results in the administration of $1 \mathrm{mU}$ of oxytocin per minute ( $1 \mathrm{mU} / \mathrm{min}$ ). There is no national consensus on an optimal oxytocin infusion regimen for induction or augmentation of labor. A commonly used low-dose regimen is an initial dose of 1 to $2 \mathrm{mU} / \mathrm{min}$, with a dose increase of 1 to $2 \mathrm{mU} / \mathrm{min}$ every 30 to $40 \mathrm{~min}$ utes until regular uterine contractions occur every 2 to 3 minutes. ${ }^{5}$ An example of a high-dose oxytocin regimen is an initial dose of $6 \mathrm{mU} / \mathrm{min}$ with an increase of 3 to $6 \mathrm{mU} / \mathrm{min}$ every 30 to 40 minutes (induction of labor). ${ }^{6}$

A randomized trial reported that, compared with a low-dose oxytocin regimen, a high-dose regimen increased the risk of tachysystole without a significant change in cesarean birth rate. ${ }^{7}$ A Cochrane review concluded that, compared with low-dose regimens, high-dose oxytocin regimens were more likely to be associated with tachysystole. ${ }^{8}$ Based on these reports, I would suggest avoiding the use of a high-dose oxytocin regimen. Experts have reported that an oxytocin dose of approximately $6 \mathrm{mU} / \mathrm{min}$ achieves a circulating oxytocin concentration similar to that observed in normal spontaneous labor. ${ }^{9}$

\section{Maximum dose of oxytocin infusion}

There is no national consensus on the maximum safe dose of oxytocin for induction or augmentation of labor. Many labor and delivery units have a protocol where the maximum dose of oxytocin is $20 \mathrm{mU} / \mathrm{min}$ for women in the following clinical situations: previous vaginal delivery, prior cesarean delivery, multiple gestation, and nulliparous women in the second stage of labor. A maximum oxytocin dose of $30 \mathrm{mU} / \mathrm{min}$ may be appropriate for nulliparous women in the first stage of labor. Some units permit an oxytocin dose of $40 \mathrm{mU} / \mathrm{min}$. Many labor nurses are concerned that an oxytocin dose that high may be associated with an increased frequency of adverse effects.

\section{Management of the oxytocin dose when tachysystole is diagnosed}

Tachysystole is defined as more than 5 uterine contractions in 10 minutes averaged over $30 \mathrm{~min}$ utes. ${ }^{5,6}$ Because uterine contractions cause a reduction in oxygen delivery to the fetus, tachysystole, prolonged uterine contractions, and sustained elevated intrauterine pressure can result in fetal hypoxia and an abnormal fetal heart rate (FHR) pattern. If tachysystole is detected and the FHR pattern is Category 1, the oxytocin dose should be reduced. If tachysystole is detected and the FHR pattern is a concerning Category 2 or Category 3 pattern, the oxytocin infusion should be discontinued until the concerning FHR pattern resolves. If tachysystole is diagnosed, changing the maternal position (ensuring a lateral maternal position) and administering an intravenous bolus of $500 \mathrm{~mL}$ of lactated Ringer's solution may help resolve an abnormal FHR. Terbutaline $0.25 \mathrm{mg}$, administered by subcutaneous injection, may be given to reduce myometrial contractility.
Following resolution of an episode of tachysystole with a concerning FHR tracing, the oxytocin infusion can be restarted at a dose less than the dose that was associated with the tachysystole.

\section{Inadvertent excess oxytocin administration}

Oxytocin only should be administered using a computerized medication infusion pump with the oxytocin line piggybacked into a main infusion line. ${ }^{5}$ Occasionally, an excessively large bolus of oxytocin is administered inadvertently because the oxytocin line was mistakenly thought to be the main line or because of an infusion pump failure. These situations usually result in a tetanic contraction that will need to be treated by the immediate discontinuation of the oxytocin infusion, a fluid bolus, and one or more doses of terbutaline.

\section{Reduction in oxytocin dose as labor progresses}

Many investigators have reported that once rapid cervical dilation is occurring, or in the second stage of labor, the dose of exogenous oxytocin often can be reduced without stalling the progress of labor. Dilation of the vagina and pelvic floor, which occurs late in the process of labor, is a powerful stimulus for the release of oxytocin from the posterior pituitary..$^{10,11}$ The marked increase in endogenous secretion of oxytocin during the second stage of labor may be the reason that the exogenous oxytocin infusion can be reduced or discontinued.

In a systematic review and meta-analysis, discontinuation of oxytocin after $5 \mathrm{~cm}$ of cervical dilation was associated with a reduced rate of uterine tachysystole and no increase in cesarean delivery. ${ }^{12}$ A Cochrane evidence-based review 
also concluded that once rapid cervical dilation is occurring, the dose of oxytocin can be reduced with a decrease in the rate of tachysystole with an abnormal FHR and without an increase in the rate of cesarean delivery. ${ }^{13}$

\section{Management of the oxytocin dose is a common cause of clinical disagreement}

As noted in two recent research studies, experienced independent professional labor nurses often feel pressured by obstetricians to increase the dose of oxytocin. One nurse reported that physicians "like the pit pushed and you'd better push it and go, go, go, otherwise they'll be...really mad if it is not going." Many obstetricians favor working with a labor nurse who will actively manage labor by aggressively increasing the oxytocin dose. One obstetrician reported, "When I hear I've got a nurse who will go up on the pit, I know it's going to be a good day." ${ }^{14}$

Obstetricians and labor nurses with a good relationship can openly discuss differing perspectives and find a compromise solution. However, if the relationship is not good, the conflict may not be resolved, and the labor nurse may use a passive- aggressive approach to the situation. As one nurse reported, "It actually depends on the doctor and his personality. I know that there were times when I had a doc who would throw a fit if I didn't up the pitocin, so I would pacify him by agreeing to, but never would." 15

An oxytocin checklist may help to reduce conflict over the optimal management of oxytocin infusion and improve patient safety. ${ }^{16}$ Practice variation among nurses, obstetricians, and nurse midwives may contribute to difficulty in achieving a consensus on how to manage oxytocin. One approach to reducing practice variation is to use checklists to improve collaboration and uniformity on a clinical team. Clark and colleagues describe the beneficial effect of both a pre-oxytocin checklist and an oxytocin in-use checklist. ${ }^{16}$ Their in-use checklist, which is completed every 30 minutes by the labor nurse, recommended decreasing the dose of oxytocin unless the FHR is reassuring and no tachysystole has occurred. In one retrospective study, when compared against outcomes prior to the use of a checklist, the use of the checklist resulted in a lower maximum dose of oxytocin (11.4 vs $13.8 \mathrm{mU} / \mathrm{min}$;
$P=.003)$, a greater 1-minute Apgar score at birth (7.9 vs $7.6 ; P=.048)$, and no increase in time to delivery ( $8.2 \mathrm{vs}$ 8.5 hours) or cesarean delivery rate (13\% vs $15 \%) .{ }^{16}$ When nurses and obstetricians collaborate using an oxytocin in-use checklist, both clinical variation and probability of conflict are reduced.

\section{Consider use of a checklist to reduce conflict}

Oxytocin infusion for induction or augmentation of labor is one of the most common and most important interventions on labor and delivery units. Oxytocin infusion practices vary widely among labor and delivery units. In addition to the lack of a consensus national standard, within any onelabor unit the perspectives of obstetricians and labor nurses regarding the management of oxytocin infusions often differ, leading to conflict. The use of an oxytocin in-use checklist may help to reduce variability and improve patient outcomes.

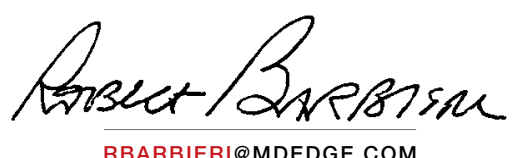

Dr. Barbieri reports no financial relationships relevant to this article.
References

1. Blanks AM, Shmygol A, Thornton S. Regulation of oxytocin receptors and oxytocin receptor signaling. Semin Reprod Med. 2007;25:52-59.

2. Fuchs AM, Romero R, Keefe D, et al. Oxytocin secretion and human parturition: pulse frequency and duration increase during spontaneous labor in women. Am J Obstet Gynecol. 1991;165: 1515-1523.

3. Fuchs AR, Fuchs F, Husslein P, et al. Oxytocin receptors in the human uterus during pregnancy and parturition. Am J Obstet Gynecol. 1984;150:734-741.

4. Seitchik J, Amico J, Robinson AG, et al. Oxytocin augmentation of dysfunctional labor. IV. Oxytocin pharmacokinetics Am J Obstet Gynecol. 1984;150:225-228.

5. Simpson KR. Cervical ripening, labor induction and labor augmentation, 5th edition. Nurs Womens Health. 2020;24:S1-S43.

6. American College of Obstetricians and Gynecolo- gists. ACOG Practice Bulletin No. 107: induction of labor. Obstet Gynecol. 2009;114:386-397.

7. Selin L, Wennerholm UB, Jonsson M, et al. Highdose versus low-dose of oxytocin for labor augmentation: a randomized controlled trial. Women Birth. 2019;32:356-363.

8. Budden A, Chen LJ, Henry A. High-dose versus low-dose oxytocin infusion regimens for induction of labor at term. Cochrane Database Syst Rev. 2014;CD00970.

9. Cuppett CD, Caritis SN. Uterine contraction agents and tocolytics. In: Mattison DR (Ed.) Clinical Pharmacology During Pregnancy. London, United Kingdom: Elsevier;2013:307-330.

10. Ferguson JK. A study of the motility of the intact uterus at term. Surg Gynecol Obstet. 1941;73: 359-366.

11. Fisher DA. Maternal-fetal neurohypophyseal system. Clin Perinatol. 1983;10:695-707.

12. Saccone G, Ciadulli A, Baxter JK, et al. Discontinu- ing oxytocin in the active phase of labor: a systematic review and meta-analysis. Obstet Gynecol. 2017;130:1090-1096.

13. Boie S, Glavind J, Velu AV, et al. Discontinuation of oxytocin in the active phase of induced labour. Cochrane Database Syst Rev. 2018;CD012274.

14. Simpson KR, James DC, Knox GE. Nurse-physician communication during labor and birth: implications for patient safety. J Obstet Gynecol Neonatal Nursing. 2006;35:547-566.

15. Simpson KR, Lyndon A. Clinical disagreements during labor and birth: how does real life compare to best practice? MCN Am J Matern Child Nurs. 2009;34:31-39.

16. Clark S, Belfort M, Saade G, et al. Implementation of a conservative checklist-based protocol for oxytocin administration: maternal and newborn outcomes. Am J Obstet Gynecol. 2007;197:480.el-e5.

17. Gawande A. The Checklist Manifesto. New York, NY: Henry Holt and Co; 2009. 